\title{
O ECA O ADOLESCENTE E O SISTEMA SOCIOEDUCATIVO - UM RECORTE JURÍDICO SOCIOLÓGICO DO ADOLESCENTE EM CONFLITO COM A LEI \\ Jeison Giovani Heiler ${ }^{1}$ \\ Joice Pacheco ${ }^{2}$
}

\section{Resumo}

Este artigo busca a partir de dados empíricos acumulados em banco de dados do Serviço de Medidas Socioeducativa em Meio Aberto do município de Jaraguá do Sul, SC identificar o perfil do adolescente em conflito com a lei. Neste objetivo articula-se informações acerca dos aspectos socioeconômicos; composição familiar; escolarização; características comportamentais, e dados relativos às medidas socioeducativas aplicadas aos adolescentes ao longo de 12 anos do serviço (1999-2011). Com base nos dados o trabalho procura dialogar com o referencial teórico da criminologia crítica e justiça restaurativa como possibilidades da completa realização do sistema de garantias inaugurado com o ECA e ainda pendente de plena efetivação.

Palavras-Chave: sistema socioeducativo; adolescente em conflito com a lei; medidas socioeducativas; criminologia crítica; justiça restaurativa

THE LAW, THE ADOLESCENTS AND THE SYSTEM OF SOCIAL EDUCATION - A LEGAL AND SOCIOLOGICAL APPROACH OF THE ADOLESCENT IN CONFLICT

WITH THE LAW

\begin{abstract}
This article seeks from empirical data accumulated in a database program for educational measures in an open environment of the city of Jaragua do Sul, SC identify the profile of adolescents in conflict with the law. This scope is structured information about the socioeconomic, family composition, education, behavioral characteristics, and data on educational measures applied to adolescents over 12 years of service (1999-2011). Based on the data he tried to talk with the theoretical framework of critical criminology and restorative justice as possible the complete realization of the guarantee system inaugurated with the ECA and still waiting for full effectiveness.
\end{abstract}

Keywords: socio system; adolescents in conflict with the law; social and educational measures; critical criminology; restorative justice.

\footnotetext{
${ }^{1}$ Graduado em Direito, Mestre em Sociologia Política - UFSC, Professor Universitário de Direitos Sociais e do Cidadão e Direito Previdenciário no Centro Universitário Católica de Santa Catarina e de Sociologia e Antropologia Jurídica, Introdução ao Estudo do Direito e Direito da Seguridade Social na Faculdade Uniasselvi/Fameg.

2 Psicóloga, pela Faculdade de Psicologia de Joinville. Especialista em Gestão na Política Nacional de Assistência Social.
} 


\section{Introdução}

A ingerência estatal, o adensamento das desigualdades sociais, o crescimento da violência na sociedade e consequentemente o sentimento coletivo de insegurança (fatores diretamente implicados) cedem passagem à respostas simplistas na tentativa de equalizar este fenômeno social típico da modernidade. Neste contexto:

A veemência dos recentes clamores pela redução da idade penal coloca em risco, como nunca, a conquista civilizatória representada pelos marcos do ECA no reconhecimento do adolescente em conflito com a lei como sujeitos de direitos plenos e em situação de peculiar de desenvolvimento. (AGUINSKY \& CAPITÃO, 2008, p. 258)

O Estatuto da Criança e do Adolescente (ECA), instituído pela Lei $n^{\circ}$ 8.069/90 contrapõe-se historicamente a um passado de controle e de exclusão social. O ECA afirma o valor intrínseco da criança e do adolescente como ser humano, a necessidade de especial respeito à sua condição de pessoa em desenvolvimento, o valor prospectivo da infância e adolescência como portadoras de continuidade do seu povo e o reconhecimento da sua situação de vulnerabilidade:

o que torna as crianças e adolescentes merecedores de proteção integral por parte da família, da sociedade e do Estado; devendo este atuar mediante políticas públicas e sociais na defesa e promoção dos seus direitos. (SINASE, 2006, p. 15)

São priorizados porque são respeitados na condição peculiar da criança e do adolescente como "pessoas em desenvolvimento" (art. $6^{\circ}$ da Lei $n^{\circ}$ 8.069/90 - Estatuto da Criança e do Adolescente). Contudo, esta noção de pessoas em desenvolvimento, faz com que surjam opiniões divergentes, especialmente no tocante ao atendimento dispensado aos adolescentes em conflito com a lei. A diversidade de opiniões vem culminando, inclusive, com a proposta de redução da idade penal de 18 para 16 anos.

Há os que consideram as medidas previstas pelo Estatuto uma verdadeira possibilidade de construção de uma vida social diferente para os adolescentes que cometem ato infracional e há os que não acreditam em mudanças para estes jovens, restando como única saída a redução da idade penal para a contenção da violência nos dias de hoje.

Também a natureza jurídica da medida socioeducativa tem dividido opiniões. De um lado há os que sustentam que a MSE é despida de caráter sancionatório e, por assim dizer, punitivo. De outro, os que afirmam que as MSE comportam aspectos de natureza coercitiva, 
vez que são punitivas aos infratores e comportam:

Aspectos educativos no sentido da proteção integral e de disponibilizar o acesso à formação e informação, sendo quem em cada medida esses elementos apresentam graduação, de acordo com a gravidade do delito cometido e/ou sua reiteração." (MAIOR NETO, 1992, p. 340)

É inegavel, contudo, que o ECA inaugurou uma nova perspectiva, de uma clara opção de inclusão social do adolescente e que se empoderamento com coaduna com a doutrina da proteção integral (SINASE, 2006, p. 15), em antítese ao velho paradigma da situação irregular (Código de Menores - Lei $\mathrm{n}^{\mathrm{o}}$ 6.697/79). Inobstante, constata-se o caráter impositivo (coercitivo), sancionatório e retributivo das medidas socioeducativas.

É impositivo, porque a medida é aplicada independentemente da vontade do infrator; é sancionatório, porque, com a ação ou omissão, o infrator quebra a regra da convivência social; é retributivo, por ser uma resposta ao ato infracional praticado". (LIBERATI , 2003, p. 127)

Todavia, embora agregada à natureza aflitiva, a medida socioeducativa, como o próprio nome sugere "é executada com finalidade pedagógico-educativa, para inibir a reincidência, como prevenção especial e garantir a efetivação da justiça" (LIBERATI, 2006, p. 370). O debate em torno da natureza das Medidas Socioeducativas, sem dúvidas é bastante acirrado, porque inserido num campo de tensão, cujas consequências podem afirmar ou não políticas públicas protetivas do Estado ao público adolescente.

Para amadurecimento do debate e sua progressão com vistas à melhor resposta social possível, faz-se necessário acumular elementos fáticos que possam enriquecer a discussão. É justamente nesta perspectiva que este trabalho espera inserir-se apresentando um recorte jurídico sociológico e antropológico do adolescente em conflito com a lei a partir do acúmulo de informações em bancos de dados que possam apontar alguns caminhos no que diz respeito às práticas infracionais e seu constrangimento por parte do Estado por intermédio do Sistema Nacional de Atendimento Socioeducativo ${ }^{3}$ e de outras práticas alternativas de juridicidade. Dados, como os que, por exemplo do ILANUD (Instituto Latino- Americano das Nações Unidas para a Prevenção do Delito e Tratamento do Delinqüente) no ano de 2000, que revelam que menos de $10 \%$ dos delitos praticados em todo país foram cometidos por

3 O Conselho Nacional dos Direitos da Criança e do Adolescente - CONANDA - editou através da Secretaria Especial dos Direitos Humanos SEDH, o SINASE - Sistema Nacional de Atendimento Sócioeducativo, convertido no Projeto de Lei 1.627/2007, documento que regula a exedcução das MSE. 
adolescentes, dos quais, apenas $8 \%$ foram contra a vida.

\title{
A representação ambivalente do adolescente
}

$\mathrm{O}$ adolescente em conflito com a lei carrega um estigma ambivalente. De um lado a sociedade de forma geral parece querer prolongar indefinidamente sua adolescência, fenômeno identificável com as práticas consumistas e de fuga das responsabilidades da vida adulta ${ }^{4}$. De outro, sem a menor cerimônia, elege a figura do adolescente como responsável pela aumento dos índices de violência e sentimento de insegurança pública “(...) que resulta fixar uma imagem pública do delinquente com componentes de classe social, étnicos, etários, de gênero e estéticos" (ZAFFARONI et al., 2003, p. 46).

No contexto das políticas públicas e do sistema socioeducativo esta visão estigmatizante acarreta em danos não somente ao adolescente:

\begin{abstract}
Aqueles que entendem que punir é sinônimo de educar não hesitam em, rapidamente, atribuir ao adolescente, autor do ato infracional, a principal responsabilidade de toda a violência social instalada no cotidiano social (...) atribuir a um determinado segmento populacional a responsabilidade pela violência, cria no imaginário social a ideia de isenção da responsabilidade coletiva na busca de alternativas para uma situação já insustentável. (AGUINSKY \& CAPITÂO, 2008, p. 261)
\end{abstract}

Fenômeno social que está de acordo com o que diz Baratta (2004, p. 210) "Las clases subalternas son, en verdad, las seleccionadas negativamente por los mecanismos de criminalización”. O escoadouro deste estigma deságua nas propostas de redução da idade penal, possibilidade de internação compulsória, imposição de "toque de recolher" limitando a permanência do adolescente nas vias públicas em determinados horários e uma série de outras medidas que, na verdade, beiram à criminalização do $s e r^{5}$ jovem. É o agigantamento do “Papai Noel”, para emprestar a lúdica metáfora de Andrade (2009, p. 51)

Percebe-se, no mesmo passo, a algumas vezes identificável segregação ocorrida nas representações do adolescente em conflito com a lei. Assim, o bom jovem, o adolescente, é este de que fala o ECA na perspectiva garantista. Aquele outro, o adolescente em conflito com a lei, é o menor delinquente, infrator, bandido em formação cujo júbilo deve ser abortado a qualquer custo. Ou, para utilizar-se da dicotomia antropológica bom selvagem $X$ mau

\footnotetext{
${ }_{5}^{4}$ Tendência explorada com maestria pelas campanhas publicitárias, senão, delas resultado mesmo.

${ }^{5} \mathrm{O}$ ser jovem é aqui abordado no seu sentido ontológico. $\mathrm{Na}$ verdade, nesse sentido, é que nos parece apresentar-se esta ambivalência.
} 
selvagem, este, é o jovem civilizado, educado e obediente. Aquele outro, é o mau selvagem, agressor, incorrigível e que precisa passar pelo processo civilizatório (socioeducativo?) mesmo que contra a sua vontade.

Teria-se assim uma estigmatização ambivalente e uma avaliação dicotômica do adolescente. Esta avaliação pode ser captada, não sem alguma dificuldade, naquilo que LéviStrauss $\left(1995\right.$, p. 34) vai denominar modelos inconscientes da sociedade ${ }^{6}$. Identificável nas manchetes e páginas policiais de jornais e periódicos impressos ou eletrônicos com alguma frequência depara-se com a seguinte formulação jornalística: "Menor Mata/Esfaqueia/Rouba Adolescente ${ }^{7}$.

Este quadro piora quando percebe-se que até mesmo entre os profissionais responsáveis pelo processo socioeducativa, muitas vezes, é manifesta a representação recriminadora do adolescente em conflito com a lei:

\begin{abstract}
Observa-se que, para esses sujeitos, a família capaz de ajudar os adolescentes seria justamente o modelo de família ideal, leia-se, família nuclear, que constitui a base da sociedade. Na medida em que esses adolescentes não se encaixam nesse modelo ideal de adolescência, as práticas dos $\mathrm{ADSs}$ são no sentido de minimizar os problemas trazidos por eles. Tais práticas baseiam-se em princípios corretivos e punitivos, como pôr de castigo nas celas e proibi-los de exercer as atividades educativas, que deveriam ser asseguradas, uma vez que fazem parte do cumprimento da pena em regime de internação. Isso nos leva a crer que antigas concepções, anteriores ao ECA, ainda perduram. A representação social dos ADSs relativas aos adolescentes parece ancorar-se nas idéias de correção e punição que pautavam a doutrina da situação regular. Esta antiga concepção não faz parte apenas da representação dos agentes sociais, mas também, e, sobretudo, da instituição, que contrata funcionários de firmas de segurança para serem os responsáveis pela guarda e proteção desses jovens. (ESPÍNDULA \& SANTOS, 2004, p. 366).
\end{abstract}

Uma das formas de discutir com estas representações recriminadoras é a acumulação de dados fáticos que possam constituir argumento a favor de uma visão multidisciplinar e mais abrangente do adolescente em conflito com a lei. Por esta razão, entre os parâmetros socioeducativos estabelecidos pelo SINASE (p. 64 e 93) está o de consolidar mensalmente os

\footnotetext{
${ }^{6} \mathrm{O}$ estruturalismo antropológico desenvolvido por Lévi-Strauss considera, na análise dos diferentes modelos de sociedades, elementos conscientes e inconscientes. Estes últimos, de dificílima assimilação, seriam responsáveis por toda representação social desprovida de fundamentos conhecidos ou conscientes. (ASSIS \& KUMPEL, 2011, p. 210) Si existe un sistema consciente, éste solamente puede ser el resultado de una especie de "media dialéctica" entre una multiplicidad de sistemas inconscientes, cada uno de los cuales concierne a un aspecto o un nivel de la realidad social. (LÉVI-STRAUSS, 1995, p. 34)

${ }^{7}$ Em rápida pesquisa: "Menor enfurecido mata adolescente com 13 facadas em praça pública" disponível em http://www.contilnet.com.br/ Conteudo.aspx?ConteudoID=11549. Acesso em 12/09/2011. "Menor mata adolescente com 2 facadas” Disponível em portaldaclube.globo.com/noticia.php?hash...id=10525. Acesso em 12/09/2011. "CN - Menor de 11 anos mata adolescente de 15 em Matinha" Disponível em http://www.1cn.com.br/ApresentaSite.asp?o=100\&t=848. Acesso em 12/09/2011.
} 
dados referentes a entradas e saídas dos adolescentes, perfil do adolescente (idade, gênero, raça/etnia, procedência, situação com o sistema de justiça, tipificação de ato infracional, renda familiar, escolarização antes e durante o cumprimento da medida, atividades profissionalizantes antes e depois do cumprimento da medida, uso indevido de drogas e registro da reincidência). Esta acumulação de dados fáticos reveste-se de importância tanto para o planejamento, monitoramento e avaliação e condução dos trabalhos, como pela contribuição que pode fornecer para quebra de estigmas, preconceitos e falsas crenças no que concerne ao adolescente em conflito com a lei. Contudo, é muito fácil se perder no emaranhado de dados. Com vistas a facilitar a leitura geral cabe sistematizar aqui algumas considerações de ordem geral.

Em primeiro lugar é necessário adotar cautela na tomada de conclusões. Os dados apresentados no cruzamento de variáveis embora estatisticamente significativos ${ }^{8}$ apresentaram coeficientes de associação na maior parte das vezes bastante baixos, o que faz com que a aceitação das associações entre os dados deva ser tomada com reservas, evitandose generalizações e determinismos. Além disso não há que se esquecer que a amostra embora extensa (1053 casos - 12 anos de serviço) comporta a realidade de apenas 1 município Jaraguá do Sul, o que é muito pouco no cenário de diversidade do País. Contudo, são dados que sempre podem trazer alguma luz ao tema.

Neste sentido cumpre iniciar apresentando-se os resultados para: 1) a análise descritiva de cada uma das variáveis relativas aos adolescentes (aspectos individuais da pessoa do adolescente e aspectos socioeconômicos; composição familiar; escolarização do adolescente; aspectos comportamentais, dados relativos às medidas socioeducativas aplicadas), e; 2) cruzamento entre variáveis no qual investigou-se possíveis associações entre variáveis buscando explicação para a reincidência e uso de substâncias psicoativas.

\section{Perfil do adolescente em conflito com a lei}

\section{a) Aspectos individuais da pessoa do adolescente e aspectos socioeconômicos}

No que tange aos aspectos individuais dos adolescentes concluiu-se que constituem uma maioria de adolescentes do sexo masculino com uma participação de adolescentes do

\footnotetext{
8 Traduzindo em miúdos: isto quer dizer que para todos os dados apresentados em cruzamentos, a fim de obter possíveis associações, as chances de que os resultados estejam se dando ao acaso são sempre inferiores a $5 \%$. O que torna estes dados aceitáveis.
} 
sexo feminino de 7,7\%, dado similar à distribuição carcerária no estado de SC. Os adolescentes em medida situavam-se em 48,6\% dos casos na faixa etária dos 16 a 17 anos. Dado que causou surpresa foi a constatação de que 43,5\% da população de adolescentes atendidos trabalhava no momento da infração

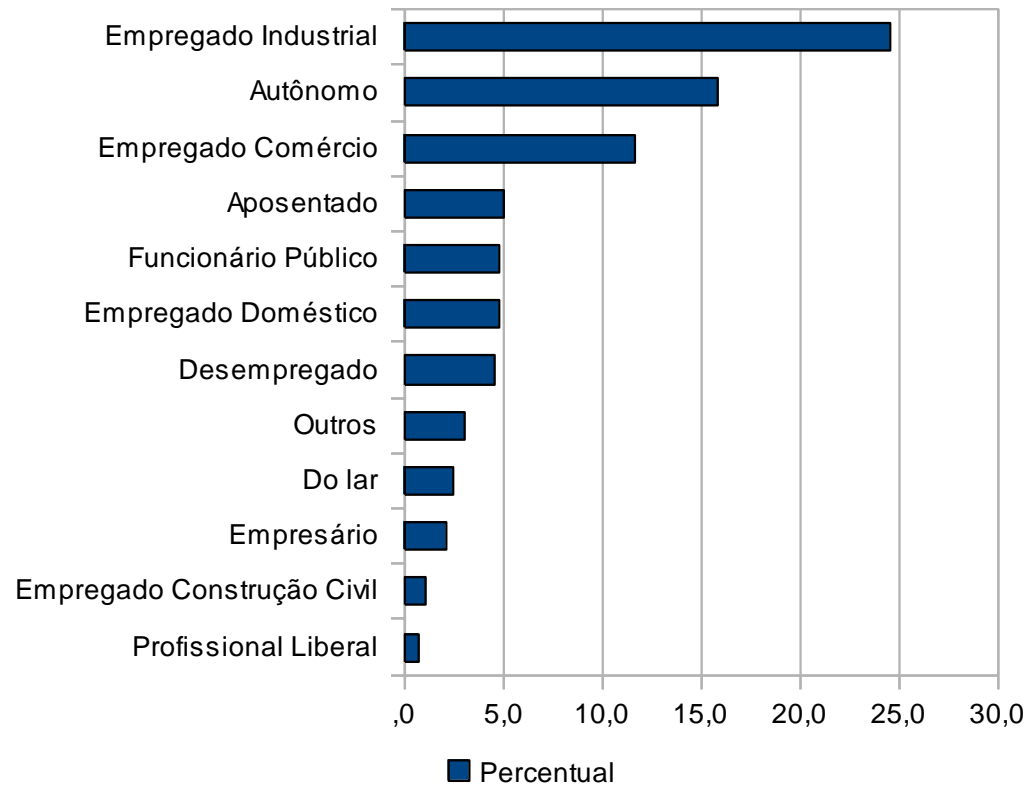

Grafico 1 - Adolescente em medida socioeducativa segundo profissão principal mantenedor familiar Fonte: Banco de dados do Programa de Medidas Socioeducativas do Município de Jaraguá do Sul, SC - 1999 2011.

Procurando traçar um perfil socioeconômico das famílias dos adolescentes trabalhouse com a variável profissão do principal mantenedor familiar. Constatou-se que $62,8 \%$ dos adolescentes em cumprimento de medida socioeducativa provêm de grupos familiares nos quais o principal mantenedor é empregado assalariado, autônomo ou aposentado. Em 7\% dos casos o grupo familiar não detinha renda própria. Em 4,7\% dos casos o mantenedor era funcionário público e apenas 2,8\% se constituíam de profissionais liberais e empresários, presumivelmente numa faixa de renda mais destacada. Quando se considera somente a renda familiar declarada observou-se que 75,7\% dos adolescentes provêm de famílias cuja renda não ultrapassa os 3 salários mínimos. Por fim, observando-se a variável que diz respeito às condições de residência dos adolescentes têm-se que $40 \%$ dos adolescentes em conflito com a lei residem em imóveis alugados, contra $51 \%$ residindo em casa própria,, comparativamente, segundo dados obtidos pelo IBGE no PNAD/2009 na região Sul do Brasil, no universo de domicílios pesquisados $70,8 \%$ constituíam-se de residências próprias, $5 \%$ de 
imóveis financiados, e $15 \%$ de imóveis alugados. Portanto, os resultados obtidos para a amostra que considera os adolescentes em medida socioeducativa reafirma que a maioria dos adolescentes em conflito com a lei provêm de famílias de condições econômicas bastante desfavoráveis.

\section{b) Composição familiar}

No que concerne à composição familiar verificou-se que a maior parte dos adolescentes em medida socioeducativa residia com ambos os pais $(53,8 \%), 24,1 \%$ conviviam com apenas a mãe, $5 \%$ com apenas o pai e 6,1\% residiam com parentes. Observou-se ainda que em quase $57 \%$ dos casos os adolescentes conviviam com pais casados ou conviventes em regime de união estável. Ao passo que em $31,1 \%$ dos casos os adolescentes conviviam com pais separados ou divorciados

\section{c) Escolarização do adolescente}

Voltando-se para a taxa de escolarização do adolescentes em cumprimento de medidas socioeducativas constatou-se que 67,6 \% dos adolescentes estavam estudando no momento da infração contra $32,3 \%$ fora da escola, ou seja, a maioria dos jovens estava inserida na escola no momento da infração. Comparativamente o relatório de pesquisa do Ministério Público Federal do DF e Territórios aponta que entre aqueles adolescentes em medida socioeducativa ${ }^{9}$ a escolarização (matrícula) é de $73,2 \%$. O que pode sugerir que em alguma medida a simples manutenção dos jovens nos bancos escolares não é suficiente para prevenção da prática infracional.

Por outro lado, no que tange ao grau de escolaridade verificou-se que $56 \%$ dos adolescentes que cumpriram a medida socioeducativa, não completaram o ensino fundamental. Um dado que, pode ser indicativo de que embora o adolescente esteja inserido na escola, não está havendo um completo envolvimento no processo de aprendizagem. Esta conclusão pode ser referendada pelos dados que mostram um déficit escolar do adolescente em conflito com a lei: i) considerando que segundo o fluxo normal de ensino o adolescente conclui o ensino fundamental aos 14 ou 15 anos, ii) Observados os adolescentes na faixa

\footnotetext{
${ }^{9}$ O Relatório não informa a que tipo de medida socioeducativa se refere, se em meio aberto como neste caso ou se envolve também medidas de internação, e semi-liberdade.
} 
etária dos 16 a 17 anos constata-se que 40,6\% não haviam concluído o ensino fundamental na idade padrão, iii) Quando considerada a faixa etária dos 18 a 21 anos o percentual de adolescentes com ensino fundamental inconcluso é ainda maior: 45,6\%, e $i v$ ) O percentual destes jovens que possuem o ensino médio completo (padrão para a idade) é de apenas 6,3\%.

Por intermédio de alguns dados escolares foi possível apreender também aspectos socioeconômicos dos adolescentes em conflito com a lei, identificando-se que os adolescentes em medida socioeducativa oriundos de escolas particulares constituem absoluta minoria: 7,4\% dos casos e que por outro lado em $32,7 \%$ dos casos o principal mantenedor familiar não possuíam mais do que o ensino fundamental incompleto, 11,2\% possuíam o ensino fundamental completo, 3,4 possuíam o ensino médio incompleto e 9,5\% o ensino médio completo. Somados os dados, em $44 \%$ dos casos os adolescentes são oriundo de famílias cujo principal mantenedor familiar não possui mais que o ensino fundamental. $\mathrm{O}$ percentual de adolescentes cujo principal mantenedor possuía ensino superior não passa de 2,5\% dos casos

\section{d) aspectos comportamentais}

Um dos fatores normalmente usado nas tentativas de explicar a prática infracional é o uso de psicoativos. A hipótese, portanto, é de que a maioria dos adolescentes atendidos fizessem uso de alguma substância psicoativa. Contudo, neste caso, esta hipótese não se confirmou, 51,7\% dos adolescentes informaram nunca terem feito uso de substâncias psicoativas. O percentual de adolescentes que informaram o uso, porém, não é nada desprezível, chegando a 37,1\%. Cabe ressaltar, mais uma vez, a decisão metodológica de agregar o uso de álcool com outras drogas, substâncias que podem diferir quanto à licitude, mas não quanto aos seus efeitos no indivíduo. A incidência é maior entre os jovens do sexo masculino. O percentual de adolescentes do sexo feminino que declarou nunca ter feito uso de quaisquer substância psicoativa chega a $60 \%$ dos casos.

Observando-se as principais práticas infracionais (Gráfico 01) vê-se que de longe os mais recorrentes são furto $36,7 \%$ e porte de entorpecentes $17,6 \%$ seguidas de brigas e/ou agressão $7,3 \%$. 


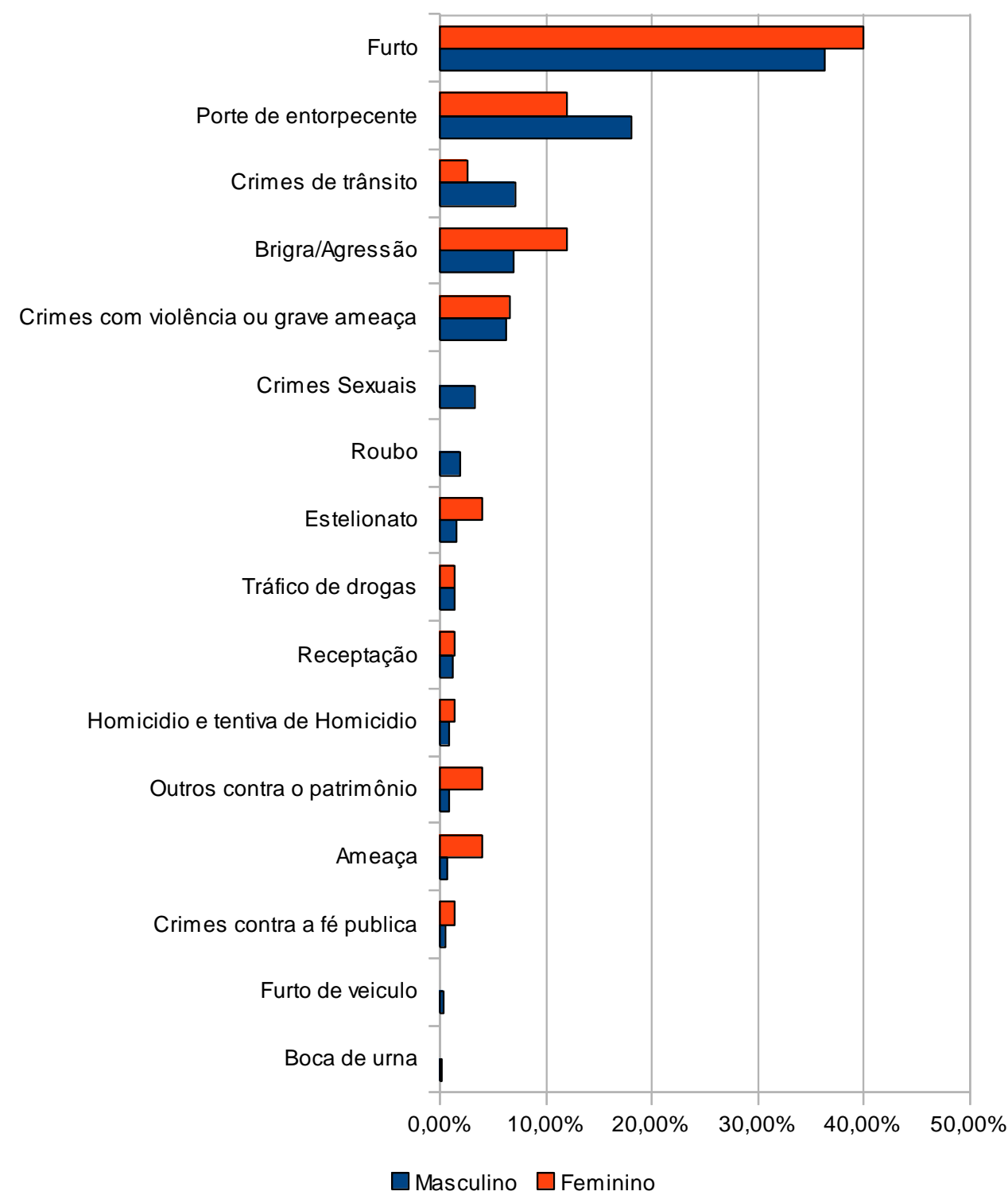

Gráfico 02 - Adolescentes em medida por sexo segundo ato infracional agrupado

Fonte: Banco de dados do Programa de Medidas Socioeducativas do Município de Jaraguá do Sul, SC - 1999 - 2011.

Juntas estas três infrações correspondem a mais de $60 \%$ das infrações cometidas pelos adolescentes. Importa notar que as infrações praticadas com violência ou grave ameaça, mesmo agregadas ${ }^{10}$, não passam de $6,4 \%$.

Digna de nota a similaridade do uso de substâncias psicoativas declarado pelas adolescentes do sexo feminino (quase $60 \%$ disseram que nunca fizeram uso) com o dado da prática de infração por porte de entorpecente, vê-se que entre as adolescentes esta prática

\footnotetext{
${ }^{10}$ As seguintes infrações estão agrupadas para formar esta categoria infracional: Assalto a Residencia, Furto com arrombamento, Porte arma de fogo, Assalto mão armada, Ameaça com arma de fogo, Assalto mão armada residencia, Lesão Corporal, Tentativa Roubo, porte de arma e entorpecente, assalto Furto + Porte de Arma, Arrombamento com Furto.
} 
infracional é bastante reduzida em relação aos adolescentes do sexo masculino. Por outro lado, a incidência das infrações equiparadas aos crimes de furto, briga/agressão, estelionato, ameaça, e crimes contra a fé publica é maior entre as adolescentes do sexo feminino.

\section{e) dados relativos às medidas socioeducativas aplicadas}

O principal de medida socioeducativa aplicada pelo juizado da infância e juventude, dentre aquelas previstas no art. 112 do ECA, quase $80 \%$ dos casos, foi a medida de Prestação de Serviços à Comunidade (na maior parte das vezes medidas de 2 a 3 meses de duração). Na ampla maioria do casos, 74,8\%, os adolescentes cumpriram regularmente a medida socioeducativa aplicada e a taxa de abandono de medida socioeducativa foi de $13,2 \%$. Em 44\% dos casos a duração da medida socioeducativa ultrapassou o prazo fixado pela justiça. Dato que pode ser explicado: a) por abandonos e faltas com necessidade de resgate ocorridos no ínterim da medida; b) períodos de férias, recesso do serviço de medidas; e c) adolescentes que ingressam no mercado do trabalho e tem o cumprimento da medida reprogramado. Contudo, esse dado merece atenção. Além dessas hipóteses explicativas, há que se manter vigilância para identificar que fatores podem estar causando este alargamento do prazo de cumprimento de uma parcela considerável das medidas socioeducativas. Fato que somente endossa a importância da construção de instrumentais como este banco de dados para a eficiente condução dos trabalhos. A maioria dos adolescentes atendidos $(51,5 \%)$ cumpriu a medida socioeducativa em instituições conveniadas (ONG's, Biblioteca Pública, Creches, Escolas e Associações Comunitárias) ao serviço. Este dado é reflexo, em parte, ao dado de que boa parte dos adolescentes trabalhava no momento da infração, tendo que executar a medida nos finais de semana e em horários alternativos. Mas também ao fato de que a medida deve ser adequada às condições do adolescente, fazendo com que em muitas vezes fosse mais apropriado o cumprimento nestas instituições. Um dos principais indicadores do fluxo de atendimento socioeducativo e que constituiu parâmetro da efetividade das intervenções do serviço é o índice de reincidência (SINASE, p. 93), nesse sentido, constatou-se que o percentual de adolescentes reincidentes em medida socioeducativas, que não ultrapassa os $20 \%$ dos casos atendidos índice que vem sendo reduzido nos últimos anos e esta na casa dos $7 \%$ no último ano da série de dados. Identificou-se que $37 \%$ dos adolescentes em cumprimento de medida socioeducativa tiveram prévia passagem por outros serviços da rede de atendimento e proteção à criança e ao adolescente. 
Dado que merece todo o destaque é o de que em apenas 2,5\% dos casos os processos de apuração do ato infracional foram acompanhados de defesa técnica por defensor dativo ou advogado em descumprimento ao que determina de forma expressa o ECA nos arts. 110, 111, III e art. $141, \S 1^{\circ}$.

\section{Teste estatístico}

No teste estatístico de hipóteses tratou-se de investigar possíveis associações entre as variáveis na tentativa de explicar a reincidência no ato infracional e o uso de psicoativos. Poucos cruzamentos, contudo, restaram com coeficientes expressivos de associação. Os quais reproduzimos abaixo:

\section{Uso Psicoativos X Composição Familiar}

Uma das questões normalmente apontada como relevante para a explicação do uso de substâncias psicoativas é a composição familiar do adolescente. Pressupõe-se normalmente que a desestrutura familiar é fator decisivo para o envolvimento do jovem com ilícitos e com uso de psicoativos. Contudo, os dados aqui acumulados desmentem em parte esta pressuposição.

Tabela 01 - Uso Psicoativos segundo pessoas com quem mora o adolescente

\begin{tabular}{|l|c|c|c|c|}
\hline \multirow{2}{*}{\multicolumn{1}{|c|}{ Composição Familiar }} & \multicolumn{3}{c|}{ Uso Psicoativos } & \multirow{2}{*}{ Total } \\
\cline { 2 - 5 } & Nunca Fez Uso & Cigarro & Alcool e Outras Drogas & 492 \\
\hline Ambos os pais & 59,4 & 8 & 32,5 & 223 \\
\hline Só com a mãe & 49,7 & 14,1 & 36,1 & 47 \\
\hline Só com o pai & 61,5 & 12,8 & 25,6 & 56 \\
\hline Parentes & 38,3 & 19,1 & 42,5 & 4 \\
\hline Cônjuge/Companheiro & 100 & 0 & 0 & 4 \\
\hline Sozinho/Amigos & 50 & 25 & 25 & 4 \\
\hline Serviços Públicos/Abrigo & 0 & 50 & 50 & 2 \\
\hline Rua & 0 & 50 & 50 & 916 \\
\hline Total & 394 & 78 & 242 & \\
\hline
\end{tabular}

Fonte: Banco de dados do serviço de Medidas Socioeducativas do Município de Jaraguá do Sul, SC - 1999 2011.

Nota-se que apesar de existir uma variação importante no que tange a associação entre uso de psicoativos e situação familiar do adolescente em conflito com a lei essa variação não possui um sentido unívoco (vê-se por exemplo uma baixa incidência entre adolescentes que 
residem apenas com o pai, e não há diferença expressiva entre o percentual de adolescentes que residem com ambos os pais ou somente com a mãe). A associação é estatisticamente significativa (Sign. 0,000), mas é ainda baixa (V Cramer - 0,294). Mas se, por um lado os dados que revelam com quem mora o adolescente não confirmavam a hipótese de que falta de estrutura familiar é decisivo no envolvimento infracional e com psicoativos, os dados relativos ao estado civil dos pais dos adolescentes em conflito com lei trazem alguma luz a este respeito. Dentre os adolescentes cujos pais eram separados ou divorciados o percentual de envolvimento com psicoativos destaca-se, atingindo $43 \%$, bastante acima do percentual entre adolescentes cujos pais estavam casados, 27,7\%. A associação é estatisticamente significativa (Sign. 0,00), mas apenas fraca (V Cramer - 0, 180).

\section{Uso Psicoativos X Evasão escolar}

A evasão escolar é um dado normalmente associado ao uso de psicoativos. Dado que se confirma no casos dos adolescentes em conflito com a lei: em 39,3\% dos casos em que estes jovens estavam fora da escola registrou-se envolvimento com psicoativos. Contra 28,5\% de incidência entre adolescentes que estavam em regular situação escolar. .

Tabela 02 - Uso psicoativos segundo situação escolar

\begin{tabular}{|l|c|c|c|c|}
\hline \multirow{2}{*}{ Situação Escolar } & \multicolumn{3}{|c|}{ Uso Psicoativos } & \multirow{2}{*}{ Total } \\
\cline { 2 - 4 } & $\begin{array}{c}\text { Nunca Fez } \\
\text { Uso }\end{array}$ & Cigarro & $\begin{array}{c}\text { Alcool e Outras } \\
\text { Drogas }\end{array}$ & \\
\hline Estudando & 62,3 & 9,4 & 28,5 & 484 \\
\hline Fora da Escola & 44,4 & 16,1 & 39,3 & 277 \\
\hline Total & 338 & 70 & 193 & 601 \\
\hline
\end{tabular}

Fonte: Banco de dados do serviço de Medidas Socioeducativas do Município de Jaraguá do Sul, SC - 1999 2011.

A associação neste caso é significativamente estatística (Sign: 0,00) e passa a ser moderada (Coef. Contingência: 0,304)

\section{Uso Psicoativos X Situação de trabalho}

O uso de psicoativos é também mais recorrente entre os adolescentes em conflito com a lei que não trabalhavam no momento da infração. Dentre estes jovens a incidência no uso de álcool e outras drogas é de $38 \%$, consideravelmente acima do incidência do uso de psicoativos entre os jovens que laboravam no momento da infração (26\%). 
Tabela 03 - Uso psicoativos segundo situação emprego

\begin{tabular}{|l|c|c|c|c|}
\hline \multirow{2}{*}{\begin{tabular}{c}
\multirow{2}{*}{$\begin{array}{c}\text { Situação } \\
\text { Emprego }\end{array}$} \\
\cline { 2 - 5 }
\end{tabular}} & \multicolumn{3}{c|}{ Uso Psicoativos } & \multirow{2}{*}{ Total } \\
\hline Trabalhava & 58,6 & 15,4 & 26 & 292 \\
\hline $\begin{array}{l}\text { Não } \\
\text { Trabalhava }\end{array}$ & 54 & 7,7 & 38,2 & 374 \\
\hline Total & 373 & 74 & 219 & 666 \\
\hline
\end{tabular}

Fonte: Banco de dados do serviço de Medidas Socioeducativas do Município de Jaraguá do Sul, SC - 1999 2011.

Aqui a associação é significativa estatisticamente (Sign: 0,00$)$ e moderada $(0,320-V$ de Cramer).

\title{
Modelos Alternativos de Juridicidade
}

É sobre este cenário fático que se insere a lógica penal dogmático-positivista, que, no dizer de Andrade:

\begin{abstract}
Afirma-se, portanto, desde sua gênese alemã e italiana, até hereditariedade que na América Latina e no Brasil alcançou, como uma ciência sistemática e eminentemente prática, a serviço de uma administração racional da justiça penal, que teria como subproduto a segurança jurídica e a justiça das decisões judiciais. Podemos demarcar, pois, no discurso dogmático, uma função declarada e oficialmente perseguida, a qual denominamos função instrumental racionalizadora/garantidora. (ANDRADE, 2009, p. 171)
\end{abstract}

Para a autora, a contrario sensu, considera-se que a ausência de uma dogmática penal implicaria o império da insegurança jurídica. Sob estes auspícios dá-se a construção do denominado código tecnológico que coloca em circulação social o ideário e a crença na segurança jurídica, contendo, a um só tempo, uma dimensão (positiva) de produção de sentido e uma dimensão (negativa) de ocultação/inversão.

A autora nesta vertente crítica questiona se de fato a matriz dogmático positivista têm conseguido cumprir suas promessas:

Tem a dogmática penal conseguido garantir os Direitos Humanos individuais contra a violência punitiva? Tem sido possível controlar o delito com igualdade e segurança jurídica? Impõe-se, neste sentido, a necessidade de uma análise relacional apta a comparar as promessas dogmáticas com a operacionalidade do sistema penal enquanto conjunto de ações e decisões e, em especial, com as decisões judiciais, pois é esta análise contrastiva que possibilita emitir juízos de (in)congruência entre operacionalidade e programação do sistema penal; ou seja, verificar se o sistema opera ou não no marco da programação normativa e dogmática e, em especial, se as decisões judiciais são de fato dogmaticamente pautadas e, por extensão, igualitárias, seguras e justas. (ANDRADE, 2009, p. 173) 
Terreno fértil para este teste contrastivo é a análise da (in)efetividade do sistema garantidor inaugurado com a Lei $n^{\circ}$. 8.069/90 instituidora da doutrina da proteção integral à criança e ao adolescente à luz do sistema socioeducativo. E cada adolescente morto nas favelas, becos ou ruelas brasileiras, cada adolescente que ocupa com suas iniciais as páginas policiais dos jornais, cada adolescente violado, cada adolescente que acende o cachimbo de Crack pela primeira vez, ou que aguarda pela vaga no banco escolar, no leito hospitalar, na linha de montagem, ou nos centros de detenção, constitui matéria para esta análise.

Com vistas a tal empreitada constitui fator elementar, como o faz Andrade (2009, p. 173), revisitar o paradigma dogmático positivista desde as suas bases, identificando, na “disputa" epistemológica com outras vertentes da ciência jurídica, as razões para o sua centralidade a partir daquele esquema proposto pela autora do sistema penal como: lócus, instrumento e parte do projeto da modernidade.

Desta forma, a temática do adolescente em conflito com a lei, implicado no sistema socioeducativo, pode ser abordada por outras formas de juridicidade (WOLKMER, 2001, p. 157). Pensar nestes modelos é autorizado quando se reflete acerca do grau de (in) efetividade das medidas socioeducativas

\footnotetext{
Ao observar a política pública socioeducativa, desvelam-se algumas situações cotidianas presentes na internação provisória, nas medidas de meio aberto e na execução da privação de liberdade, tanto na internação quanto na semiliberdade, que violam direitos humanos dos internados. (AGUINSKY \& CAPITÂO, 2008, p. 261)
}

Costa e Assis (2006) para falar da inefetividade do sistema socioeducativo na aplicação das medidas socioeducativas chamam a atenção para dizer que, independentemente de sua modalidade, tais medidas devem produzir impactos positivos na vida dos adolescentes

Contudo, as dificuldades em sua implementação não têm permitido superar o estigma da predição de fracasso atribuído aos adolescentes autores de ato infracionais e ao próprio sistemasocioeducativo (Oliveira, 2003; Oliveira \& Assis, 1999 apud Costa e Assis (2006, p. 76).

Com o cuidado de não se fazer tabula rasa das conquistas implementas pelo ECA pode-se problematizar, a partir destes limites, a máxima efetividade do sistema socioeducativo a partir de outros modelos de juridicidade. Com vistas a este escopo, imperativo é a apropriação de outros saberes, para que se amplie a compreensão acerca da prática infracional 
na adolescência. Vários são os estudos ${ }^{11}$ que demonstram a relevância do contexto social do adolescente, da institucionalização ${ }^{12}$ e de agentes de risco ${ }^{13}$ que causam a vulnerabilizarão do adolescente. Deste modo o período da medida socioeducativa, para o adolescente, será dotado de significativa importância para o desenvolvimento, sobretudo por ser esta uma fase em que as mudanças - biológicas, cognitivas, emocionais e sociais - são vivenciadas de modo bastante intenso. "Na adolescência ocorre um aumento da variabilidade de experiências de vida e de demandas sem que haja equivalente incremento de suportes sociais e recursos disponíveis para lidar com tantas situações" (Silva \& Hutz, 2002 apud Costa \& Assis, 2006, p. 76).

Desta forma o cometimento do ato infracional não é explicado pela presença isolado de um fator adverso ou de características individuais e culpabilizantes. Ele se dá em virtude de uma cadeia de acontecimentos e eventos na trajetória do adolescente. Assim, cabe dotar, este sujeito em peculiar situação de desenvolvimento, de elementos e capacidades de resistência às adversidades geradoras de risco, promovendo aquilo que na área do serviço social vai se chamar de resiliência

\begin{abstract}
Entendida enquanto potencial ou capacidade que o ser humano desenvolve no sentido de superar adversidades e continuar sua trajetória de vida de forma mais favorável (Pesce, Assis, Santos \& Oliveira, 2004), a resiliência não tem por finalidade eliminar os riscos ou tornar o sujeito "invulnerável", mas encorajá-lo a lidar efetivamente com a situação e sair fortalecido da mesma. Ainda que esse conceito careça de univocidade, corresponde a um processo que é simultaneamente social e intrapsíquico, e que remete à "capacidade de encontrar forças para transformar intempéries em perspectivas" (Assis et al., 2006, p. 57 Apud Costa \& Assis, 2006, p. 77).
\end{abstract}

Nesse contexto a abordagem do sistema socioeducativo pode ser feita também pela via da justiça restaurativa e outros modelos de juridicidade. Nesse sentido no dizer de Aguinsky \& Capitão (2008, p. 264) a Justiça Restaurativa no sistema de Justiça da Infância e Juventude "implica numa mudança de ótica e uma nova ética na significação das violências em relação às situações lavadas a jurisdição da execução das medidas socioeducativas".

\footnotetext{
${ }^{11}$ Costa e Assis (2006, p. 76) destacam os seguintes (Neiva-Silva \& Koller; 2002; Silva \& Hutz, 2002; Yunes, Miranda \& Cuello, 2004).

12 "As instituições podem "influenciar a trajetória de vida das crianças e adolescentes, de maneira a inibir ou incentivar o desenvolvimento psicológico sadio" (Miranda \& Cuello, 2004, p. 198). De modo semelhante, Siqueira, e Dell'Aglio (2006) abordam estudos que vislumbram os efeitos negativos da institucionalização, bem como outros nos quais as instituições puderam prover apoio social a crianças e adolescentes, favorecendo o desenvolvimento de aspectos saudáveis mesmo diante de adversidades" (Apud Costa e Assis 2006, p. 76)

13 Por risco entende-se "todo tipo de eventos negativos de vida que, quando presentes, aumentam a possibilidade do indivíduo apresentar problemas físicos, sociais ou emocionais" (Yunes \& Zsymanski, 2001, apud Costa e Assis 2006, p. 76)
} 
A Justiça Restaurativa segundo leciona Thaís Luzia Colaço (2010) baseia-se num procedimento de consenso, em que

\begin{abstract}
a vítima e o infrator, e, em alguns casos, outros membros da comunidade afetados pelo crime, participam coletiva e ativamente na construção de soluções para a cura dos traumas e perdas causados pelo crime. Trata-se de um processo voluntário, informal, sem o peso e o ritual solene do cenário judiciário, e podendo ser utilizadas técnicas de mediação, conciliação e transação para se alcançar um acordo objetivando suprir as necessidades individuais e coletivas das partes e se lograr a reintegração social da vítima e do infrator. (COLAÇO, 2010, p. 282)
\end{abstract}

Através de práticas de justiça restaurativa o foco muda do culpado para as consequências da ação infracional. O que sem sombra de dúvida implica na virada hermenêutica necessária ao rompimento com os dogmas positivistas. Trata-se de abandonar "a busca por culpados e da mera punição para a construção de reconhecimento social de todos os envolvidos e de proposições compartilhadas de reparação, superação e prevenção dos danos" (COLAÇO, 2010, p. 277 e ss). De acordo com essa lógica as responsabilidades passam a fazer sentido para todos: ofensores, vítimas, para a rede de atendimento e também para a comunidade.

\title{
Referências Bibliográficas
}

ABONG/DCA. Adolescência Ato Infracional \& Cidadania. Brasília-DF, 1999

AGUINSKY, Beatriz; CAPITÂO, Lúcia. Violência e Socioeducação: uma interpelação ética a partir da contribuição da justiça restaurativa. Revista Katálysis. Florianópolis v. 11 n. 2 p. 257-264 jul./dez. 2008.

ANDRADE, Vera Regina Pereira. Flagrando a ambiguidade da dogmática penal com a lupa criminológica: que garantismo é possível do compasso criminologia - penalismo crítico? In: Revista Seqüência, no 59, p. 161-192, dez. 2009. Disponível em: http://periodicos.ufsc.br/index.php/sequencia/article/viewFile/14151/13594. Acesso em 30/08/2011.

;Minimalismos e abolicionismos: a crise do sistema penal entre a deslegitimação e a expansão. Revista da ESMESC, v.13, n. 19, 2006.

AGUINSKY, Beatriz and CAPITAO, Lúcia. Violência e socioeducação: uma interpelação ética a partir de contribuições da Justiça Restaurativa. Rev. katálysis [online]. 2008, vol.11, n.2, pp. 257-264. ISSN 1414-498

BARATTA, Alessandro. Criminologia Crítica Y Crítica del Derecho Penal. Introducción a la sociologia jurídico-penal. 1. Ed. 1. reimp. Buenos Aires: Siglo XXI Editores Argentina. 2004. 
BRASIL. Presidência da República. Secretaria Especial dos Direitos Humanos. Conselho Nacional dos Direitos da Criança e do Adolescente. Sistema Nacional De Atendimento Socioeducativo - SINASE. Secretaria Especial dos Direitos Humanos - Brasília-DF: CONANDA, 2006.

Estatuto da Criança e do Adolescente. Lei Federal 8.069, de 13 de julho de 1990. Brasília: Secretaria de Estado dos Direitos Humanos, Departamento da Criança e do Adolescente, 2002.

Constituição Federal. Brasília: Esplanada, 2002

CELLA, Silvana Machado; CAMARGO, Dulce Maria Pompêo de. Trabalho pedagógico com adolescentes em conflito com a lei: feições da exclusão/inclusão. Educ. Soc., Campinas, $\quad$ v. 30, n. 106, Apr. $2009 \quad$. $\quad$ Disponível em $<$ http://www.scielo.br/scielo.php?script=sci_arttext\&pid=S010173302009000100014\&lng=en\&nrm=iso $>$ access on 30 Aug. 2011. http://dx.doi.org/10.1590/S0101-73302009000100014.

COLACO, Thais Luzia. Elementos De Antropologia Jurídica. 2a Edição. Editora Conceito Editorial, 2010.

ESPINDULA, Daniel Henrique Pereira and SANTOS, Maria de Fátima de Souza. Representações sobre a adolescência a partir da ótica dos educadores sociais de adolescentes em conflito com a lei. Psicol. estud. [online]. 2004, vol.9, n.3, pp. 357-367. ISSN 1413-7372.-81232007000500015\&lng=en\&nrm=iso>. access on 30 Aug. 2011. http://dx.doi.org/10.1590/S1413-81232007000500015.

HEILER, JEISON GIOVANI. LIESENBERG, KITIANE, C. ULRICH. Dados do Adolescente em Conflito com a Lei - Medidas Socioeducativas em Meio Aberto Prestação de Serviços à Comunidade e Liberdade Assistida - Município de Jaraguá do Sul - SC - Relatório Parcial. In: CONGRESSO JOINVILLENSE DE PSICOLOGIA, 2. 2009. Joinville. Anais. Disponível em <http://www.ace.br/facul_psicologia_congressos.asp. $>$ acesso em 18/05/2010.

LÉVI-STRAUSS, Claude. Antropología Estructural. 2. Reimpressão 1995. Barcelona: Ed. Paidós. 1995

LIBERATI, Wilson Donizeti; FERREIRA, Luiz Antonio Miguel. Execução de Medidas em Meio Aberto - Prestação de Serviços à Comunidade e Liberdade Assistida. In ILANUD; ABMP; SEDH; UNFPA (orgs) Justiça Adolescente e ato infracional: socioeducação e responsabilização. São Paulo: ILANUD, 2006.

LOPES, LUCIANO SANTOS. A contribuição de Alessandro Baratta para a criminologia crítica. De jure: revista juridica do Ministério Público do Estado de Minas Gerais, Belo Horizonte, n. 11, 2008.

MAIOR NETO, et al. Garantias penais do adolescente autor de ato infracional. In ILANUD; ABMP; SEDH; UNFPA (orgs) Justiça Adolescente e ato infracional: socioeducação e 
responsabilização. São Paulo: ILANUD, 2006.

MARTIN-CHENUT, Kathia Regina. Adolescente em conflito com a lei: O modelo de intervenção preconizado pelo direito internacional dos direitos humanos. In Revista do ILANUD. Textos Reunidos. No 24. 2003. p. 79-102.

NICKNICH, Mônica. Direito Penal Juvenil: A negação da cidadania ao adolescente. In: Âmbito Jurídico, Rio Grande, 49, 31/01/2008 [Internet]. Disponível em url $=$ location;document.write(url); http://www.ambitojuridico.com.br/site/index.php?n_link=revista_artigos_leitura\&artigo_id=4173. Acesso em 30/08/2011.

PRIULI, Roseana Mara Aredes; MORAES, Maria Silvia de. Adolescentes em conflito com a lei. Ciênc. saúde coletiva, Rio de Janeiro, v. 12, n. 5, Oct. 2007 . Available from $<$ http://www.scielosp.org/scielo.php?script=sci_arttext\&pid=S1413

WOLKMER, Antonio Carlos. Pluralismo Jurídico: fundamentos de uma nova cultura no Direito. 3. ed. São Paulo: Alfa Omega, 2001.

ZAFFARONI, E. R. et al., Direito Penal Brasileiro. Rio de Janeiro: Revan, 2003 